\title{
Why is phloem sap nitrate kept low?
}

\author{
Jing $\mathrm{Cui}^{1}$, Andreas D. Peuke ${ }^{2}$, Anis Limami ${ }^{3}$, and Guillaume Tcherkez ${ }^{4}$ \\ ${ }^{1} \mathrm{ANU}$ \\ ${ }^{2}$ ADP International Plant Science Consulting \\ ${ }^{3}$ University of Angers, (IRHS 1345) Institute of Research of Horticulture and Seeds \\ ${ }^{4}$ Affiliation not available
}

March 18, 2021

\begin{abstract}
Since the first description of phloem sap composition nearly 60 years ago, it is generally assumed that phloem sap does not contain nitrate and that there is little or no backflow of nitrate from shoots to roots. While it is true that nitrate can occasionally be absent from phloem sap, there is now substantial evidence that phloem can carry nitrate and furthermore, transporters involved in nitrate redistribution to shoot sink organs and roots have been found. This raises the question of why nitrate may or may not be present in phloem sap, why its concentration is generally kept low, and whether plant shoot-root nutrient cycling also involves nitrate. We propose here that phloem sap nitrate is not only an essential component of plant nutritional signaling but also contributes to physical properties of phloem sap and as such, its concentration is controlled to ensure proper coordination of plant development and nutrient transport.
\end{abstract}

\section{Introduction}

It has now been 61 years since phloem sap composition has first been described, using sap extracted from willow (Peel \& Weatherley, 1959). In that study, using colorimetric methods, nitrate was found to be undetectable. Several subsequent studies also reported the absence of nitrate in other species such as castor bean (Ricinus communis ) (Hall \& Baker, 1972) and overviews of phloem sap composition established the generally very low, or undetectable, concentration in phloem sap nitrate (Ziegler, 1975). Furthermore, experiments with ${ }^{15} \mathrm{~N}$-nitrate labelling in legumes have shown that nitrate could not be transported from xylem to phloem at detectable levels (Pate, Sharkey, \& Lewis, 1975). There are more recent reports where nitrate was found to be undetectable, for example in maize (Lohaus et al., 2000). It is thus widely accepted that phloem sap nitrate is of negligible importance and in particular, that nitrate circulation from shoots to roots does not occur. For example, in a recent review, the backflow of nitrate via the phloem to regulate root development is not mentioned (Fig. 3 in (Tegeder \& Masclaux-Daubresse, 2018)). Also, in textbooks and university lectures, it is often reported that nitrate is absent from phloem sap and thus does not flow back from shoots to roots, see for example (Taiz, Zeiger, Moller, \& Murphy, 2015). However, many pieces of recent evidence suggest the contrary and provide possible reasons explaining why phloem nitrate concentration is usually low. They are presented in this Opinion.

\section{Phloem sap may contain nitrate}

In fact, there are noticeable exceptions where nitrate is not absent from phloem sap composition (Fig. 1a-f). It is the case of cereals (wheat, rice), with phloem sap nitrate of up to $8 \mathrm{mM}$ (Hayashi \& Chino, 1985; Hayashi \& Chino, 1986). Also, in palm trees, nitrate has been found in phloem exudates for either trunk and inflorescence peduncles (van Die \& Tammes, 1975). Extensive analysis of castor bean phloem sap has shown that average nitrate phloem concentration is $0.59 \mathrm{mM}$, ranging from no detectability to $2.4 \mathrm{mM}$ (Peuke, 2010). This is of course much less than in xylem, which contains up to $25 \mathrm{mM}$ nitrate. Interestingly, nitrate 
has been found to be much more abundant in phloem $(0.29 \mathrm{mM})$ than xylem sap $(3 \mu \mathrm{M})$ in Western candle tree (Banksia prionotes ) (Jeschke \& Pate, 1995). These findings cannot be explained by the technique of sap collection (i.e. potential adulteration by other tissues upon sampling). The above-cited studies used very different techniques (aphid-stylet and pure phloem sap exudation) and therefore a systematic contamination is unlikely. In effect, nitrate can be found in phloem sap using the aphid stylet method (i.e. involving stylectomy), which gives access to very high purity phloem sap (van Helden, Tjallingh, \& van Beek, 1994).

\section{Nitrate redistribution via phloem sap circulation}

Nitrate redistribution via phloem circulation has been recently suggested to occur in three physiological contexts (Fig. 1g), supported by the characterization of nitrate transporters in Arabidopsis : remobilization from leaves, development of reproductive structures and nitrate backflow from shoots to roots.

\section{Nitrate transfer and remobilization in leaves}

Three nitrate transporters have been shown to be involved in nitrate transfer and/or redistribution to the phloem from xylem or source nitrate-containing tissues: NPF2.13/NRT1.7, NPF1.1/NRT1.12, and NRT1.2/NRT1.11 (Iqbal et al., 2020). In particular, it has been recently shown that NPF2.13/NRT1.7 is essential for remobilization of nitrate from old leaves to deliver nitrate into the phloem, making it available for new, developing leaves and enhancing nitrogen use efficiency (Chen, Chen, Tseng, \& Tsay, 2020). NPF1.1/NRT1.12 and NPF1.2/NRT1.11 have been found to be involved in the transfer of xylem nitrate to phloem in the petiole thereby facilitating nitrate remobilization from mature (old) leaves to young leaves (Hsu \& Tsay, 2013).

\section{Development of reproductive structures}

Up to now, two nitrate transporters have been shown to be of importance in silique and seeds: NPF2.12/NRT1.6, and NPF5.5. NPF2.12/NRT1.6 is capable of transporting both nitrate and gibberellin $\mathrm{GA}_{1 / 3}$, and is expressed intensively in funiculus vascular bundles, which are mostly made of phloem tissue inArabidopsis (Almagro, Lin, \& Tsay, 2008). InNPF2.12/NRT1.6 mutants, mature seeds contain effectively less nitrate, suggesting that NPF2.12/NRT1.6 is involved in transporting nitrate from maternal tissue to the developing embryo via the phloem (Almagro et al., 2008). NPF5.5, which as been shown to transport nitrate, is involved in controlling embryo $\mathrm{N}$ content: in knock-out mutants, embryos at the bent cotyledon stage have a 7-8\% reduction in the $\mathrm{N}$ content suggesting that the import of nitrate to the developing seed has been impacted (Léran et al., 2015).

Nitrate backflow from shoots to roots

Two nitrate transporters are related to nitrate flow from shoots to roots: NPF2.9/NRT1.9, and NPF1.1/NRT1.12. NPF2.9/NRT1.9 is expressed in root phloem. In NPF2.9/NRT1.9 mutants, the nitrate content in root phloem exudates is lower (by 20 to 30\%) (Wang \& Tsay, 2011); furthermore, downwards nitrate transport to root tips, when assayed with a compartmentalized root system, is reduced, suggesting that NPF2.9/NRT1.9 effectively plays a role in the backflow of nitrate to roots (Wang \& Tsay, 2011). Unlike NPF1.2/NRT1.11, NPF1.1/NRT1.12 is expressed in roots (not only in shoots) and since it is involved in xylem-to-phloem nitrate transfer (Hsu \& Tsay, 2013), it suggests that it can be involved in nitrate cycling to roots.

Taken as a whole, there is substantial evidence that some nitrate transporters allow nitrate transfer and circulation into the phloem either downwards (to roots) or upwards (to seeds and young leaves). In addition, although nitrate is not the major nitrogen form in the phloem, the strong growth retardation phenotype observed in theNPF1.2/NRT1.11 NPF1.1/NRT1.12 double mutant (Hsu \& Tsay, 2013) suggests that phloem-mediated nitrate redistribution is essential.

\section{Is phloem sap nitrate a signaling molecule?}

There is now considerable evidence that nitrate can play a signaling role to control plant development (Kant, 2018) and nitrate redistributed by the phloem seems to participate in this control (summarized in Fig. 2). 
Historically, an important step forward was the demonstration that nitrate shoot content acts as a signal to regulate the shoot:root ratio. In fact, manipulating nitrate reductase activity showed a correlation between leaf nitrate concentration and shoot:root ratio, across different levels of nitrate supply (Scheible, Lauerer, Schulze, Caboche, \& Stitt, 1997). Furthermore, in split-root experiments, root growth is inhibited by the accumulation of nitrate in the shoot, regardless of the fact that one part of the root system was supplied with high nitrate and the other part with low nitrate (Scheible et al., 1997). More recently, split-root experiments have shown that there is a cytokinin-mediated signaling from the root part under low $\mathrm{N}$ conditions, so as to promote lateral root development in the root part under N-rich conditions (Ruffel et al., 2011).

The signaling cascade associated with nitrate has been dissected recently and shown to involve $\mathrm{Ca}^{2+}$-sensor protein kinases and NIN-like proteins (NLP) transcription factors to control gene expression, including genes encoding enzymes and transporters involved in nitrogen assimilation (Chu et al., 2020; Liu et al., 2017). In addition, at the plant scale, nitrate signaling involves small peptides transited via phloem sap. The signaling peptide C-TERMINALLY ENCODED PEPTIDE 1 (CEP1) is produced by roots under N deficiency, and transported to the shoot via the xylem, leading to the induction of the signaling peptides CEP DOWNSTREAM 1 (CEPD1) and CEPD2; these peptides are then transported to roots via the phloem and upregulates the high affinity nitrate transporter NRT2.1 (Gu et al., 2018; Ohkubo, Tanaka, Tabata, Ogawa-Ohnishi, \& Matsubayashi, 2017).

In such a molecular context, could phloem nitrate itself have a signaling role? It might be so, in particular in root tips where longitudinal root growth (increase in root length) occurs. It is worth noting that in root tips, protophloem develops first, that is, before protoxylem (Bauby, Divol, Truernit, Grandjean, \& Palauqui, 2007; Mahonen et al., 2000). Also, in root tips, nitrate absorption is very small, compared to other root sections (Lazof, Rufty, \& Redinbaugh, 1992). Therefore, root tip metabolism depends on the import of organic N, not nitrate. We can thus speculate that the influx of nitrate via protophloem could contribute to determine root tip nitrate concentration which has in turn a regulatory role. In effect, in Legumes, nitrate inhibits primary root growth at the root tip via NPF6.8-mediated abscisic acid signaling and reactive oxygen species (Limami \& Morere-Le Paven, 2019; Pellizzaro et al., 2014; Zang et al., 2020). In Arabidopsis, nitrate stimulates meristematic activity (primary root growth) at the root tip via cytokinin signaling (Naulin et al., 2020).

If nitrate transported by phloem sap plays effectively a signaling role, it raises two questions: $(i)$ First, nitrate concentration in phloem must be controlled to avoid both fluctuations and high concentrations. That is, signal-carrying molecules have to be at low concentration under steady-state conditions and their transient increase can play the role of a signal. Unfortunately, relatively little is known on possible fluctuations of nitrate concentration in phloem sap and whether its appearance in sap is linked to specific circumstances (although there is some correlation with xylem nitrate and other nutrients, see below, Perspectives for $N$ cycling in plants ). (ii ) Second, unclear would be the reason to have both CEP- and nitrate-based regulation of root growth. That said, while CEP-based regulation seems to be associated with low N signaling, nitrate itself could represent a more generic $\mathrm{N}$ status signal (not only low $\mathrm{N}$ conditions). It is now well established that nitrate interacts with many hormones such as cytokinins (Sakakibara, Takei, \& Hirose, 2006), and this aspect has been reviewed elsewhere recently (Vega, O'Brien, \& Gutierrez, 2019). Taken as a whole, nitrate concentration itself could participate in defining the signaling milieu and thus the flow of nitrate from shoots to roots via the phloem could be important to control root growth.

\section{Low nitrate concentration may avoid protein aggregation}

Phloem sap contains very high content of sucrose (about $400 \mathrm{mM}$ in castor bean and palms, for example), amino acids (about $60 \mathrm{mM}$ in most species, up to $140 \mathrm{mM}$ in some trees) and $\mathrm{K}^{+}$(about $60 \mathrm{mM}$, up to 500 $\mathrm{mM}$ in Salix , (Peel \& Weatherley, 1959)). $\mathrm{Mg}^{2+}$ and $\mathrm{Na}^{+}$are present in lower abundance and $\mathrm{Ca}^{2+}$ is at low concentration (1 mM or less) (Ziegler, 1975). Anions that counterbalance $\mathrm{K}^{+}$high content are mostly $\mathrm{Cl}^{-}$, phosphate, sulphate and organic acids (malate). Nitrate is thus a minor participant in phloem electroneutrality. Also, phloem sap contains significant amounts of proteins, at about $1 \mathrm{~g} \mathrm{~L}^{-1}$, and an important proportion is made of the so-called P-proteins (SEOR proteins inArabidopsis ) that are believed to play 
a role in phloem occlusion by $\mathrm{Ca}^{2+}$-dependent aggregation (Anstead, Froelich, Knoblauch, \& Thompson, 2012; Jekat et al., 2013; Knoblauch, Froelich, Pickard, \& Peters, 2014; van Bel et al., 2014). Of course, phloem sap contains many other proteins, and recent proteomics analyses have shown that this includes not only enzymes, but also translation initiation or elongation factors, proteins involved in redox homeostasis, chaperones, etc. (Rodriguez-Celma, Ceballos-Laita, Grusak, Abadia, \& Lopez-Millan, 2016). It is worth mentioning that with such high salt concentration (in particular $\mathrm{K}^{+}$), there is a risk of uncontrolled protein aggregation. In fact, both experiments and theory have provided evidence that ion species have different propensity to trigger protein aggregation (chaotropism), via denaturation and/or instability (Kunz, 2010). $\mathrm{Ca}^{2+}$ is the most chaotropic cation while tertiary amines are the least chaotropic, $\mathrm{K}^{+}$being intermediate. This provides a physical justification for the role of $\mathrm{Ca}^{2+}$ in phloem occlusion. Similarly for anions, phosphate, sulphate and organic acids are the least chaotropic, but nitrate is much more chaotropic, just behind perchlorate and iodide (Kunz, 2010). Accordingly, experiments with lysozyme have demonstrated that the displacement of the solubilization-aggregation equilibrium towards aggregation is larger with nitrate than chloride forms of sodium salts (Kastelic, Kalyuzhnyi, Hribar-Lee, Dill, \& Vlachy, 2015). As such, having high concentrations of nitrate is not desirable for phloem protein stability when $\mathrm{K}^{+}$(and/or $\mathrm{Mg}^{2+}$ ) is present at high concentration. Conversely, in vitro, in sucrose concentrated solutions (at concentrations similar to that found in phloem sap), ethylamine nitrate has been found to be beneficial to protein renaturation and decreases viscosity due to the rescuing property of ethylamine as a non-chaotropic cation (Byrne, Wang, Belieres, \& Angell, 2007).

\section{Nitrate cycling in plants}

While there might be good reasons to explain why nitrate concentration must remain low in phloem sap (signaling and chaotropism), the occasional presence of nitrate raises the question of its potential role in nutrient cycling. Incubation with a nitrate-containing buffer (10 mM nitrate) of castor bean cotyledons (the endosperm being removed) have shown that nitrate can be found (at about $1 \mathrm{mM}$ ) in phloem sap exudated from cut hypocotyls, suggesting that nitrate cycling via the phloem is effectively possible (Schobert \& Komor, 1992). Furthermore, pioneering $\mathrm{N}$ mass balance in castor bean proposed that nearly $50 \%$ of nitrate translocated to the shoot cycled back to roots (Marschner, Kirkby, \& Engels, 1997). While this number is certainly overestimated, recent isotopic data $\left({ }^{15} \mathrm{~N}\right.$ natural abundance, $\left.\delta^{15} \mathrm{~N}\right)$ also suggest that a small flux of a few percent of xylem translocation to shoots can cycle back to roots, in both sunflower and oil palm (Cui, Lamade, Fourel, \& Tcherkez, 2020). Although quantitatively minor, this flux is important to explain the natural, considerable ${ }^{15} \mathrm{~N}$-enrichment in root nitrate: in fact, nitrate reduction in shoots discriminates between $\mathrm{N}$ isotopes in favor of ${ }^{14} \mathrm{~N}$ and thus ${ }^{15} \mathrm{~N}$-nitrate left behind is redistributed to roots via the phloem. Also, since nitrate redistributed to the phloem is naturally ${ }^{15} \mathrm{~N}$-enriched, it is possible that variations in phloem sap nitrate concentration along the day contribute to explaining the diel pattern of $\delta^{15} \mathrm{~N}$ of phloem in castor bean (Peuke, Gessler, \& Tcherkez, 2013). Interestingly, the $\delta^{15} \mathrm{~N}$ value of aphids (feeding on phloem sap) has been shown to be lower $\left({ }^{15} \mathrm{~N}\right.$-depleted) compared to host plants and related to nitrate reduction capacity, suggesting that the aphid-host isotopic difference is partly explained by the natural ${ }^{15} \mathrm{~N}$-enrichment in phloem nitrate, as opposed to the ${ }^{15} \mathrm{~N}$-depletion in phloem amino acids (Wilson, Sternberg, \& Hurley, 2011).

The backflow of nitrate from shoots to roots depends on growth conditions impacting on overall nutrition, since (Cui et al., 2020) showed it depends on K nutrition and root hypoxia (waterlogging). The interaction between $\mathrm{K}$ nutrition and nitrate absorption has been known for decades and has been mostly explained by the key role of $\mathrm{K}^{+}$as a counteraction for nitrate (Casadesús, Tapia, \& Lambers, 1995; Coskun, Britto, \& Kronzucker, 2017; Wang \& Wu, 2013). Accordingly, the nitrate transporter NPF7.3/NRT1.5 has been shown to act as an antiporter with $\mathrm{K}^{+} / \mathrm{H}^{+}$(Li et al., 2017). Nevertheless, there is no significant relationship between nitrate and $\mathrm{K}^{+}$concentrations in phloem (Peuke, 2010) and this might not be surprising because $\mathrm{K}^{+}$is present at very high concentration in phloem. Interestingly, phloem sap nitrate increases when nitrate availability increases and declines with salinity (Peuke, Glaab, Kaiser, \& Jeschke, 1996). Meta-analyses have shown that phloem nitrate concentration does not correlate significantly to other cations and only correlates with xylem, leaf and root nitrate content (Peuke, 2010). However, the nitrate flow in the phloem (expressed in 
$\mu$ mol nitrate $\mathrm{g}^{-1} \mathrm{FW} \mathrm{d}^{-1}$ ) correlates reasonably well with phloem carbon and $\mathrm{Ca}^{2+}$ flows (Peuke, 2010). The nitrate backflow thus depends on other nutrients and salinity and is maybe linked to metabolites (organic acids and amino acids) present in phloem sap. The supply of amino acids to roots via the phloem participates in the control of root $\mathrm{N}$ acquisition (for a specific discussion, see (Tillard, Passama, \& Gojon, 1998)) and as discussed above, nitrate also plays a regulatory role. Thus, more than individual concentrations, the nitrate-to-amino acid ratio of phloem sap might be a crucial component of plant development, root growth and nitrogen assimilation. In the past years, there have been an increasing number of publications on phloem (including proteomics data) but due to the difficulty of phloem sap collection, there is limited information on phloem composition under varying conditions, including metabolite profiling (metabolomics), nitrate content and $\delta^{15} \mathrm{~N}$ value.

\section{Open questions for future research}

Taken as a whole, key questions that are still unanswered and deserve more research can be summarized as follows:

1. What is the rationale of phloem sap nitrate variation between species? As stated above, the range of concentration is very large (from non-detectability to nearly $10 \mathrm{mM}$ ). Uncertainty remains as to whether this is related to $\mathrm{N}$ allocation, efficiency of nitrate remobilization from leaves to developing organs, or different strategies in $\mathrm{N}$ status signaling.

2. Does phloem nitrate contribute effectively to nitrate signaling and growth regulation? For example, is the response to nitrate modified when phloem nitrate transport is compromised? Is the xylem-tophloem ratio of nitrate concentration or phloem nitrate-to-amino acid ratio indicators of $\mathrm{N}$ status?

3. Do the relationships between nutrients, xylem nitrate and phloem nitrate still hold in species other that castor bean? Up to now, there is no such extensive dataset like that obtained in this species.

4. Is low nitrate concentration an essential factor to avoid protein aggregation in phloem sap? Can experiments be designed where nitrate is trapped or added to manipulate protein aggregation propensity?

Future studies are warranted to provide more insight on these aspects and thus to clarify the roles of nitrate found in phloem sap and also demonstrate why it is kept at a very low concentration in many cases.

\section{Acknowledgements}

The authors acknowledge the financial support of the Région Pays de la Loire and Angers Loire Métropole via the grant Connect Talent Isoseed awarded to G.T.

\section{Data availability}

There is no data associated with this manuscript.

\section{References}

Almagro, A., Lin, S. H., \& Tsay, Y. F. (2008). Characterization of the Arabidopsis nitrate transporter NRT1.6 reveals a role of nitrate in early embryo development. The Plant Cell, 20 (12), 3289-3299.

Anstead, J. A., Froelich, D. R., Knoblauch, M., \& Thompson, G. A. (2012). Arabidopsis P-Protein Filament Formation Requires Both AtSEOR1 and AtSEOR2. Plant and Cell Physiology, 53 (6), 1033-1042.

Bauby, H., Divol, F., Truernit, E., Grandjean, O., \& Palauqui, J.-C. (2007). Protophloem differentiation in early Arabidopsis thalianadevelopment. Plant and Cell Physiology, 48 (1), 97-109.

Byrne, N., Wang, L.-M., Belieres, J.-P., \& Angell, C. A. (2007). Reversible folding-unfolding, aggregation protection, and multi-year stabilization, in high concentration protein solutions, using ionic liquids. Chemical Communications (26), 2714-2716.

Casadesús, J., Tapia, L., \& Lambers, H. (1995). Regulation of $\mathrm{K}^{+}$and $\mathrm{NO}_{3}{ }^{-}$fluxes in roots of sunflower (Helianthus annuus) after changes in light intensity. Physiologia Plantarum, 93 (2), 279-285. 
Chen, K.-E., Chen, H.-Y., Tseng, C.-S., \& Tsay, Y.-F. (2020). Improving nitrogen use efficiency by manipulating nitrate remobilization in plants. Nature Plants, 6 (9), 1126-1135.

Chu, L. C., Offenborn, J. N., Steinhorst, L., Wu, X. N., Xi, L., Li, Z., . . . Schulze, W. X. (2020). Plasma membrane $\mathrm{CBL} \mathrm{Ca}^{2+}$ sensor proteins function in regulating primary root growth and nitrate uptake by affecting global phosphorylation patterns and microdomain protein distribution. New Phytologist, In press.

Coskun, D., Britto, D. T., \& Kronzucker, H. J. (2017). The nitrogen-potassium intersection: membranes, metabolism, and mechanism. Plant Cell and Environment, 40 (10), 2029-2041.

Cui, J., Lamade, E., Fourel, F., \& Tcherkez, G. (2020). $\delta^{15} \mathrm{~N}$ values in plants are determined by both nitrate assimilation and circulation. New Phytologist, 226 (6), 1696-1707.

Gu, J., Li, Z., Mao, Y., Struik, P. C., Zhang, H., Liu, L., . . . Yang, J. (2018). Roles of nitrogen and cytokinin signals in root and shoot communications in maximizing of plant productivity and their agronomic applications. Plant Science, 274, 320-331.

Hall, S. M., \& Baker, D. A. (1972). The chemical composition ofRicinus phloem exudate. Planta, 106 (2), 131-140.

Hayashi, H., \& Chino, M. (1985). Nitrate and other anions in the rice phloem sap. Plant and Cell Physiology, 26 (2), 325-330.

Hayashi, H., \& Chino, M. (1986). Collection of pure phloem sap from wheat and its chemical composition. Plant and Cell Physiology, 27 (7), 1387-1393.

Hsu, P.-K., \& Tsay, Y.-F. (2013). Two phloem nitrate transporters, NRT1.11 and NRT1.12, are important for redistributing xylem-borne nitrate to enhance plant growth. Plant Physiology, 163 (2), 844-856.

Iqbal, A., Qiang, D., Alamzeb, M., Xiangru, W., Huiping, G., Hengheng, Z., . . . Meizhen, S. (2020). Untangling the molecular mechanisms and functions of nitrate to improve nitrogen use efficiency. Journal of the Science of Food and Agriculture, 100 (3), 904-914.

Jekat, S. B., Ernst, A. M., von Bohl, A., Zielonka, S., Twyman, R. M., Noll, G. A., \& Prüfer, D. (2013). P-proteins in Arabidopsis are heteromeric structures involved in rapid sieve tube sealing. Frontiers in Plant Science, 4, Article 225.

Jeschke, W. D., \& Pate, J. S. (1995). Mineral nutrition and transport in xylem and phloem of Banksia prionotes (Proteaceae), a tree with dimorphic root morphology. Journal of Experimental Botany, 46 (8), 895-905.

Kant, S. (2018). Understanding nitrate uptake, signaling and remobilisation for improving plant nitrogen use efficiency.Seminars in Cell and Developmental Biology, 74, 89-96.

Kastelic, M., Kalyuzhnyi, Y. V., Hribar-Lee, B., Dill, K. A., \& Vlachy, V. (2015). Protein aggregation in salt solutions. Proceedings of the National Academy of Sciences, 112 (21), 6766-6770.

Knoblauch, M., Froelich, D. R., Pickard, W. F., \& Peters, W. S. (2014). SEORious business: structural proteins in sieve tubes and their involvement in sieve element occlusion. Journal of Experimental Botany, 65 (7), 1879-1893.

Kunz, W. (2010). Specific ion effects in colloidal and biological systems. Current Opinion in Colloid $\mathcal{E}$ Interface Science, 15 (1-2), 34-39.

Lazof, D. B., Rufty, T. W., \& Redinbaugh, M. G. (1992). Localization of nitrate absorption and translocation within morphological regions of the corn root. Plant Physiology, 100 (3), 1251-1258. 
Léran, S., Garg, B., Boursiac, Y., Corratgé-Faillie, C., Brachet, C., Tillard, P., . . . Lacombe, B. (2015). AtNPF5.5, a nitrate transporter affecting nitrogen accumulation in Arabidopsis embryo.Scientific Reports, 5 (1), Article 7962.

Li, H., Yu, M., Du, X.-Q., Wang, Z.-F., Wu, W.-H., Quintero, F. J., . . Wang, Y. (2017). NRT1.5/NPF7.3 functions as a proton-coupled $\mathrm{H}^{+} / \mathrm{K}^{+}$antiporter for $\mathrm{K}^{+}$loading into the xylem in Arabidopsis. The Plant Cell, 29 (8), 2016-2026.

Limami, A. M., \& Morère-Le Paven, M.-C. (2019). Nitrate signaling pathway via the transporter MtNPF6.8 involves abscisic acid for the regulation of primary root elongation in Medicago truncatula In F. De Bruijn (Ed.), The model legume Medicago truncatula (pp. 118-124). Hoboken: John Wiley \& Sons, Wiley Blackwell.

Liu, K.-h., Niu, Y., Konishi, M., Wu, Y., Du, H., Chung, H. S., . . . Maekawa, S. (2017). Discovery of nitrate-CPK-NLP signalling in central nutrient-growth networks. Nature, 545 (7654), 311-316.

Lohaus, G., Hussmann, M., Pennewiss, K., Schneider, H., Zhu, J. J., \& Sattelmacher, B. (2000). Solute balance of a maize (Zea mays L.) source leaf as affected by salt treatment with special emphasis on phloem retranslocation and ion leaching. Journal of Experimental Botany, 51 (351), 1721-1732.

Mähönen, A. P., Bonke, M., Kauppinen, L., Riikonen, M., Benfey, P. N., \& Helariutta, Y. (2000). A novel two-component hybrid molecule regulates vascular morphogenesis of the Arabidopsis root. Genes and Development, 14 (23), 2938-2943.

Marschner, H., Kirkby, E. A., \& Engels, C. (1997). Importance of cycling and recycling of mineral nutrients within plants for growth and development. Botanica Acta, 110 (4), 265-273.

Naulin, P. A., Armijo, G. I., Vega, A. S., Tamayo, K. P., Gras, D. E., de la Cruz, J., \& Gutiérrez, R. A. (2020). Nitrate induction of primary root growth requires cytokinin signaling in Arabidopsis thaliana .Plant and Cell Physiology, 61 (2), 342-352.

Ohkubo, Y., Tanaka, M., Tabata, R., Ogawa-Ohnishi, M., \& Matsubayashi, Y. (2017). Shoot-to-root mobile polypeptides involved in systemic regulation of nitrogen acquisition. Nature Plants, 3 (4), Article no. 17029.

Pate, J. S., Sharkey, P. J., \& Lewis, O. A. M. (1975). Xylem to phloem transfer of solutes in fruiting shoots of legumes, studied by a phloem bleeding technique. Planta, 122 (1), 11-26.

Peel, A. J., \& Weatherley, P. E. (1959). Composition of sieve-tube sap.Nature, 184 (4703), 1955-1956.

Pellizzaro, A., Clochard, T., Cukier, C., Bourdin, C., Juchaux, M., Montrichard, F., . . Morère-Le Paven, M.-C. (2014). The nitrate transporter MtNPF6.8 (MtNRT1.3) transports abscisic acid and mediates nitrate regulation of primary root growth in Medicago truncatula .Plant Physiology, 166 (4), 2152-2162.

Peuke, A. (2010). Correlations in concentrations, xylem and phloem flows, and partitioning of elements and ions in intact plants. A summary and statistical re-evaluation of modelling experiments in Ricinus communis . Journal of Experimental Botany, 61 (3), 635-655.

Peuke, A., Gessler, A., \& Tcherkez, G. (2013). Experimental evidence for diel $\delta^{15} \mathrm{~N}$-patterns in different tissues, xylem and phloem saps of castor bean (Ricinus communis L.). Plant, Cell and Environment, 36 (12), 2219-2228.

Peuke, A., Glaab, J., Kaiser, W. M., \& Jeschke, W. D. (1996). The uptake and flow of C, N and ions between roots and shoots inRicinus communis L. IV. Flow and metabolism of inorganic nitrogen and malate depending on nitrogen nutrition and salt treatment. Journal of Experimental Botany, 47 (296), 377-385.

Rodríguez-Celma, J., Ceballos-Laita, L., Grusak, M. A., Abadía, J., \& López-Millán, A.-F. (2016). Plant fluid proteomics: Delving into the xylem sap, phloem sap and apoplastic fluid proteomes. Biochimica et Biophysica Acta (BBA) - Proteins and Proteomics, 1864 (8), 991-1002. 
Ruffel, S., Krouk, G., Ristova, D., Shasha, D., Birnbaum, K. D., \& Coruzzi, G. M. (2011). Nitrogen economics of root foraging: Transitive closure of the nitrate-cytokinin relay and distinct systemic signaling for $\mathrm{N}$ supply vs. demand. Proceedings of the National Academy of Sciences of the USA, 108 (45), 18524-18530.

Sakakibara, H., Takei, K., \& Hirose, N. (2006). Interactions between nitrogen and cytokinin in the regulation of metabolism and development. Trends in Plant Science, 11 (9), 440-448.

Scheible, W.-R., Lauerer, M., Schulze, E.-D., Caboche, M., \& Stitt, M. (1997). Accumulation of nitrate in the shoot acts as a signal to regulate shoot-root allocation in tobacco. The Plant Journal, 11 (4), 671-691.

Schobert, C., \& Komor, E. (1992). Transport of nitrate and ammonium into the phloem and the xylem of Ricinus communis seedlings. Journal of Plant Physiology, 140 (3), 306-309.

Taiz, L., Zeiger, E., Moller, I., \& Murphy, A. (2015). Plant physiology and development (Sixth Edition ed.). Sunderland, Massachusetts: Sinauer Associates Inc.

Tegeder, M., \& Masclaux-Daubresse, C. (2018). Source and sink mechanisms of nitrogen transport and use. New Phytologist, 217 (1), 35-53.

Tillard, P., Passama, L., \& Gojon, A. (1998). Are phloem amino acids involved in the shoot to root control of $\mathrm{NO}_{3}{ }^{-}$uptake in Ricinus communisplants? Journal of Experimental Botany, 49 (325), 1371-1379.

van Bel, A. J. E., Furch, A. C. U., Will, T., Buxa, S. V., Musetti, R., \& Hafke, J. B. (2014). Spread the news: systemic dissemination and local impact of $\mathrm{Ca}^{2+}$ signals along the phloem pathway. Journal of Experimental Botany, 65 (7), 1761-1787.

van Die, J., \& Tammes, P. (1975). Phloem exudationfrom Monocotyledonous axes. In M. Zimmermann \& J. Milburn (Eds.), Transport in plants I. Phloem transport (pp. 196-222). Berlin: Springer.

van Helden, M., Tjallingh, W. F., \& van Beek, T. A. (1994). Phloem sap collection from lettuce (Lactuca sativa L.): Chemical comparison among collection methods. Journal of Chemical Ecology, 20 (12), 3191-3206.

Vega, A., O’Brien, J. A., \& Gutiérrez, R. A. (2019). Nitrate and hormonal signaling crosstalk for plant growth and development. Current Opinion in Plant Biology, 52 , 155-163.

Wang, Y., \& Tsay, Y.-F. (2011). Arabidopsis nitrate transporter NRT1.9 is important in phloem nitrate transport. The Plant Cell, 23 (5), 1945-1957.

Wang, Y., \& Wu, W.-H. (2013). Potassium transport and signaling in higher plants. Annual review of plant biology, 64, 451-476.

Wilson, A. C. C., Sternberg, L. d. S. L., \& Hurley, K. B. (2011). Aphids alter host-plant nitrogen isotope fractionation.Proceedings of the National Academy of Sciences, 108 (25), 10220-10224.

Zang, L., Morère-Le Paven, M.-C., Clochard, T., Porcher, A., Satour, P., Mojović, M., . . . Montrichard, F. (2020). Nitrate inhibits primary root growth by reducing accumulation of reactive oxygen species in the root tip in Medicago truncatula . Plant Physiology and Biochemistry, 146 , 363-373.

Ziegler, H. (1975). Nature of transported substances. In M. Zimmermann \& J. Milburn (Eds.), Transport in plants I. Phloem transport(Vol. 1, pp. 59-100). Berlin: Springer.

\section{Hosted file}

image1.emf available at https://authorea.com/users/383909/articles/514182-why-is-phloem-sapnitrate-kept-low

Figure 1. Nitrate circulation via phloem sap : (a-f) Typical species where phloem nitrate has been directly measured or inferred from isotopic mass-balance: palm trees (van Die \& Tammes, 1975) (a), cereals (wheat and rice) (Hayashi \& Chino, 1985; Hayashi \& Chino, 1986) (b), Western candle tree Banksia prionotes (Jeschke \& Pate, 1995) (c), castor bean (Peuke, 2010) (d), sunflower (Cui et al., 2020) (e), and Arabidopsis 
(Wang \& Tsay, 2011) (f). (g) Summary of processes involving nitrate circulation via phloem sap (see text for further details).

\section{Hosted file}

image2.emf available at https://authorea.com/users/383909/articles/514182-why-is-phloem-sapnitrate-kept-low

Figure 2. Summary of potential roles played by phloem nitrate in signaling for growth regulation. This figure is a simplification and does not mention transporters involved in nitrate transport and sensing (see text for further details). Pathways are sub-divided into xylem (green) and phloem (red) mediated signaling. Abbreviations: CaPK, calcium-dependent protein kinases; CEP, C-terminally encoded peptide; CEPD, CEP downstream; NLP, NIN-like proteins; ROS, reactive oxygen species.
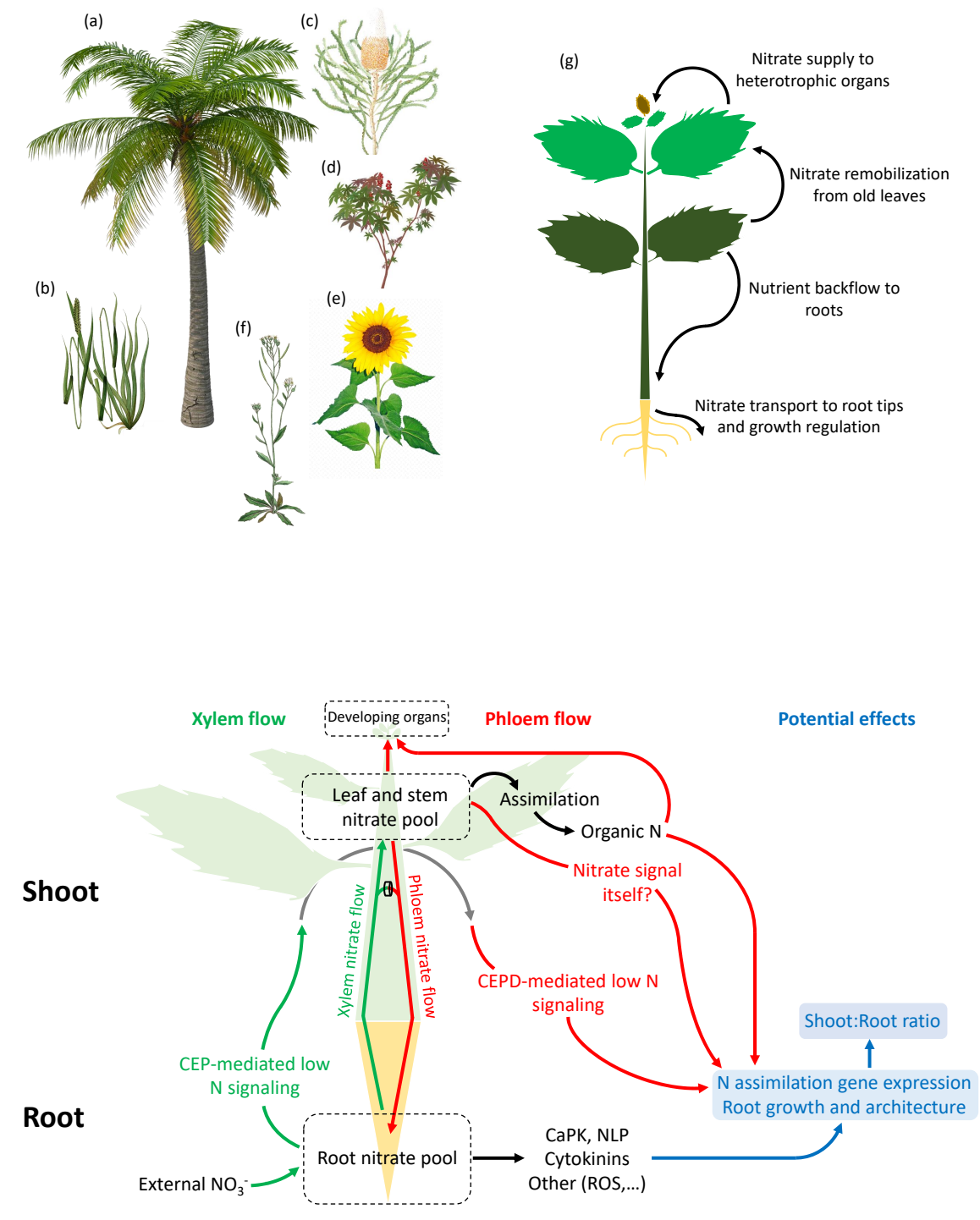